\title{
Nanomaterials Synthesis, Applications, and Toxicity
}

\author{
Mallikarjuna Nadagouda, ${ }^{1}$ Thomas F. Speth, ${ }^{2}$ Christopher Impellitteri, ${ }^{3}$ and Yuliang Zhao ${ }^{4}$ \\ ${ }^{1}$ National Risk Management Research Laboratory, US Environmental Protection Agency, 26 West MLK Drive, Cincinnati, \\ OH 45268, USA \\ ${ }^{2}$ Water Supply and Water Resources Division, US EPA, 26 West Martin Luther King Drive, Cincinnati, OH 45268, USA \\ ${ }^{3}$ Water Quality Management Branch, US Environmental Protection Agency, ORD/NRMRL/WSWRD-MS 679, \\ 26 West Martin Luther King Drive, Cincinnati, OH 45268, USA \\ ${ }^{4}$ The Research Center for Cancer Nanotechnology, National Center for Nanosciences and Technology of China, \\ Tianjin Cancer Hospital \& CAS, P.O. Box 918, Beijing 100049, China
}

Correspondence should be addressed to Mallikarjuna Nadagouda, nadagouda.mallikarjuna@epa.gov

Received 11 August 2011; Accepted 11 August 2011

Copyright (C) 2011 Mallikarjuna Nadagouda et al. This is an open access article distributed under the Creative Commons Attribution License, which permits unrestricted use, distribution, and reproduction in any medium, provided the original work is properly cited.

This issue presents a wide variety of insightful work in the synthesis, characterization, and properties of nanomaterials.

Researchers continuously strive to improve material properties and develop novel methods for nanosynthesis. For example, M. Srivastava et al. report a novel method for increasing hydrophobicity of $\mathrm{ZnO}$ surfaces through the incorporation of polytetrafluoroethylene (PTFE). The modification of $\mathrm{ZnO}$ with PTFE results in a decreased treatment time, and such a material is easily modified by either stearic acid or fluoroalkylsilane to give a low-energy superhydrophobic material. Polymeric materials have also been found useful in nanoscale templates. S. L. Pang et al. present a novel route to the formation of thin-film $\mathrm{MnO}_{2}$ by self-assembly of $\mathrm{MnO}_{2}$ nanoparticles on nickel-coated polyethylene terephthalate utilizing a horizontal submersion process at room temperature. These materials exhibit high capacitance behavior, high cycling reversibility, and stability within the potential range of 0.0 to $0.9 \mathrm{~V}$ based on cyclic voltammetry. Furthermore, C. Dwivedi et al. report the synthesis of polyvinyl-alcohol-(PVA-) stabilized selenium nanoparticles by reaction of sodium selenosulfate with various organic acids in room-temperature aqueous media. Although a gamut of organic acids and various PVA concentrations were studied, no significant effects on structure were found. Simply, the spherical selenium nanoparticles ranged in size from about 40 to $100 \mathrm{~nm}$, as readily seen in AFM and TEM imaging.
Soft matter has also played a role in nanoscale synthesis. In this issue, W. N. R. W. Isahak et al. present a comparative study of silicotungstic acid bulk (STAB) and STA-silica sol gel (STA-SG) and their efficacies, both in activity and selectivity, as catalysts in an esterification reaction. STA-SG resulted in lower conversion (96\%) compared to STAB (100\%) and control $\mathrm{H}_{2} \mathrm{SO}_{4}$ (98\%); however, STA-SG advantageously delivers selectivity of $95 \%$ compared to 89.9 and $81.6 \%$ by using STAB and $\mathrm{H}_{2} \mathrm{SO}_{4}$, respectively. Such attributes may result from the increased surface area obtained by the sol gel method.

In a different synthetic route, Y. Zhao et al. report the synthesis of $\mathrm{Ni} / \mathrm{Al}$ layered double hydroxide (LDH) nanorods by a hydrothermal method. Such methods require a $\mathrm{pH}$ of 10.0 and temperature of $180^{\circ} \mathrm{C}$ for nanorod formation. Additionally, reaction time increases not only rod diameter, but also rod length.

The ability to tune magnetic properties of nanoparticles has recently garnered interest in many groups. S. Singhal et al. analyzed cobalt-substituted nickel chromium ferrites $\left(\mathrm{CrCo}_{x} \mathrm{Ni}_{1-x} \mathrm{FeO}_{4}, x=0,0.2,0.4,0.6,0.8\right.$, and 1.0) prepared by a sol gel autocombustion method at various annealing temperatures. Here, as annealing temperature increases, particle size increases up to $45 \mathrm{~nm}$, and added $\mathrm{Co}^{3+}$ content increases saturation magnetization and decreases coercivity.

Similarly, R. Shaiboub et al. discusse the demagnetization effects of increasing Er concentrations on nanoparticle $\mathrm{Y}_{3-x} \mathrm{Er}_{x} \mathrm{Fe}_{5} \mathrm{O}_{12}(x=0.2,1.0$, and 2.0) thin films synthesized 
by a solgel method. Such films obtain a single-phase garnet and begin crystallization at $800^{\circ} \mathrm{C}$, and with increased annealing temperature, the material displays larger crystallite sizes. The loss of magnetization with increased Er content was attributed to the reverse alignment between $\mathrm{Er}^{3+}$ and $\mathrm{Fe}^{3+}$. In contrast to the sol gel method, H. Y. He reports that the properties of $\mathrm{Co}_{0.5} \mathrm{Zn}_{0.5} \mathrm{Fe}_{2} \mathrm{O}_{4}$ nanoparticles formed by a carboxymethyl cellulose template hydrothermal method were analyzed by XRD, SEM, and vibrating sample magnetometer. The increase of template proportion in synthesis results in not only morphological change from granular to platelike but also an increase in superparamagnetic behavior (from $2.81 \mathrm{~T}$ without template to $3.13 \mathrm{~T}$ with template).

The application of reported nanomaterials is an important topic for researchers. S. Kaviya et al. report the utilization of Polyalthia longifoli leaf extract as both a reducing and capping agent with D-sorbitol for increased stabilization in the synthesis of silver nanoparticles (AgNPs). Additionally, UV-vis spectroscopy revealed a blue shift with increased reaction temperature. These synthesized materials were found to have a wider antimicrobial activity in grampositive than gram-negative organisms.

Moreover, nanoparticles have found use not only as catalysts, but also as materials for environmental remediation. In the field of catalysis, Z. M. Wang et al. elucidate the important parameters in flame aerosol synthesis of pure $\mathrm{TiO}_{2}$ and $\mathrm{TiO}_{2}$ doped with $\mathrm{Fe}$ or V. Here, the photocatalytic properties of the synthesized material were studied by the selective oxidation of 1-phenyl ethanol to acetophenone. The introduction of a Fe or V dopant resulted in increased catalytic activity at lower concentrations of deposited metal ions. Additionally, the morphology of neat $\mathrm{TiO}_{2}$ alters with increased metal doping as witnessed in XRD analysis and the Raman spectroscopy. Researchers compared the efficacy of the photocatalyst in both acetonitrile and water and found the organic solvent to provide higher conversion.

In regards to remediation, S. R. Kanel et al. reports the synthesis of nanoscale ( 20 to $50 \mathrm{~nm}$ ) hydroxyapatite (NHA) through vigorous agitation of $\mathrm{Ca}\left(\mathrm{NO}_{3}\right)_{2} \cdot 4 \mathrm{H}_{2} \mathrm{O}$ and $\left(\mathrm{NH}_{4}\right)_{2} \mathrm{HPO}_{4}$ in alkaline solution. In uranium removal studies, the precipitate performed comparably to commercially available HA. Based on two-dimensional flow cell analysis, the synthesized NHA exhibits transport properties akin to tracers in aqueous environments; consequently, potential applications may include in situ $\mathrm{U}(\mathrm{VI})$ remediation. Additionally, M. N. Nadagouda and D. A. Lytle present the novel synthesis of iron oxide/iron-coated carbons like activated carbon, anthracite, cellulose fiber, and silica by combustion and their uses in arsenic adsorption. Generally, the spherical nanoparticles ranged in size from 50 to $400 \mathrm{~nm}$. Such materials were found suitable for arsenic adsorption and may be suitable in environmental remediation, catalysis, and various other applications.

Mallikarjuna Nadagouda

Thomas F. Speth

Christopher Impellitteri

Yuliang Zhao 

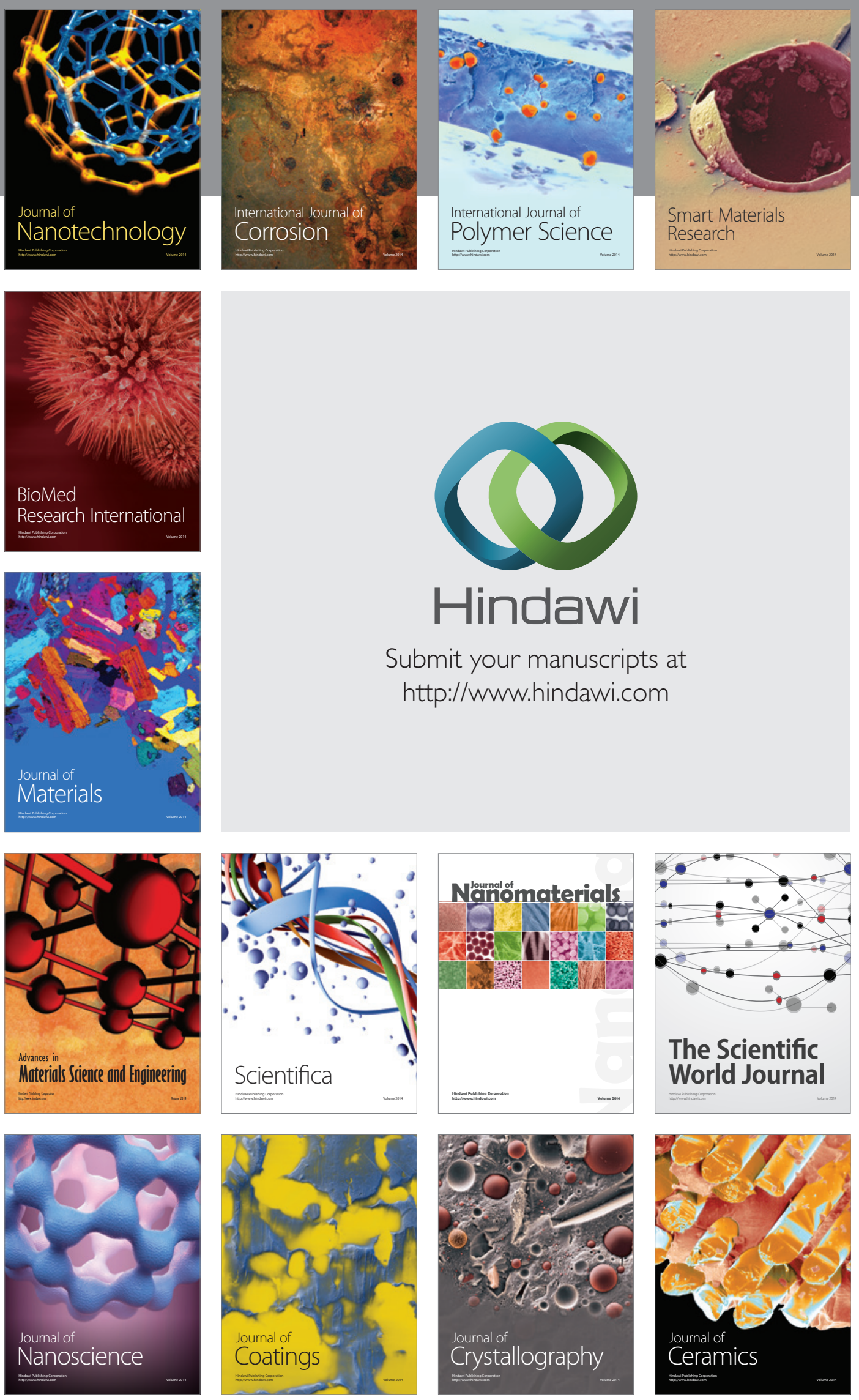

The Scientific World Journal

Submit your manuscripts at

http://www.hindawi.com

\section{World Journal}

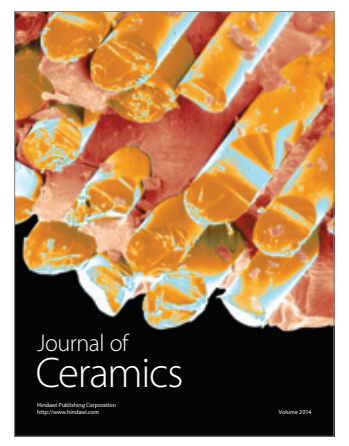

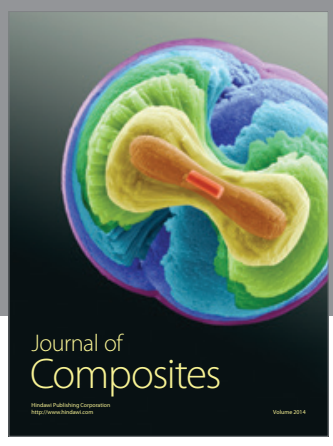
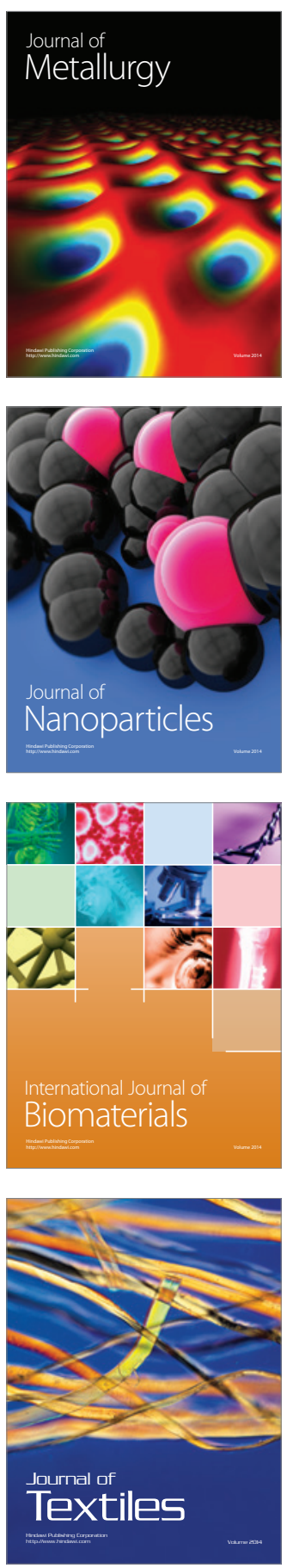